\title{
REVIEW \\ Caregiving services in spinal cord injury: a systematic review of the literature
}

\author{
EM Smith ${ }^{1,2,3}, \mathrm{~N}$ Boucher $^{4}$ and WC Miller ${ }^{2,3,5}$ and the SCIRE Research Team
}

Study design: PRISMA guided systematic review.

Objectives: To summarize and characterize the literature pertaining to the nature of and factors associated with caregiving services provided to individuals with spinal cord injury $(\mathrm{SCl})$ and identify areas for interventional research to address the needs of care recipients.

Data Sources: PUBMED/Medline, CINAHL, PsycINFO, EMBASE, Social Services Abstracts and Social Work Abstracts databases.

Methods: Qualitative and quantitative peer-reviewed publications that were written in English were included if they described the nature of caregiving services in $\mathrm{SCl}$, factors influencing the use of and access to caregiving services or described interventions to address caregiving needs of individuals with $\mathrm{SCl}$.

Results: Sixteen papers were selected. The level of evidence for included studies ranged from 2 (highest) to 5 (lowest). Eleven studies described the nature of caregiving services, demographics of caregivers and recipients and factors associated with requiring care. Five studies described caregiving interventions.

Conclusion: Caregiving services in SCl are predominantly provided by informal caregivers who are female. Quality of care from informal caregivers matches or exceeds quality of formal care. Total hours of care are dependent on the injury level and severity and care needs of the individual. Caregiver training is an important theme and has positive preliminary results on the quality of care provided. Intervention-based research is limited; further research to increase independence in activities of daily living and instrumental activities of daily living would reduce the need for caregiving hours.

Spinal Cord (2016) 54, 562-569; doi:10.1038/sc.2016.8; published online 23 February 2016

\section{INTRODUCTION}

Access to advances in medical technology in the developed world has increased survival rates for those sustaining a spinal cord injury (SCI), ${ }^{1}$ and many individuals are living longer with the effects of the condition. ${ }^{2}$ Functional impairments due to SCI are highly variable and may impact a person's capacity to engage in activities of daily living (ADL) and social participation. Individuals with higher levels of injury may require complete assistance with ADLs, which has the potential to impact social participation, whereas those with lower or incomplete injuries may experience more independence in all areas. ${ }^{3}$ Regardless of the impairment, these individuals often experience some reliance on caregivers for day-to-day needs.

Caregiving services can be defined broadly as home-based supports (paid or unpaid) that assist individuals to perform basic and instrumental ADLs (BADLs and IADLs-including personal care, household management and financial management), which they would not otherwise be able to perform independently., ${ }^{4,5}$ This care, typically provided on a part-time basis, often reduces the costs associated with institutional or formal care. ${ }^{6}$ Through ongoing assistance with BADLs and IADLs for individuals with SCI, caregivers can improve access to the community and increase social participation, including employment and adapted sports and recreation opportunities. ${ }^{2}$

Paid caregiving services may come at a high financial cost to either the individual or the funding agency involved. ${ }^{7}$ However, research suggests that the majority of caregiving services for individuals with disabilities are provided by unpaid, informal caregivers, largely comprising family members and spouses. ${ }^{8,9}$ Understanding the roles of these caregivers, particularly in providing high-quality services, is important to ensuring that individuals with SCI remain as healthy and independent as possible as they go through life..$^{10,11}$ In Canada, caregiving is estimated to cost between $\$ 12000$ and \$51 000 annually, depending on the type of injury, ${ }^{7}$ whereas the annual mean cost of care in the USA has been estimated at $\$ 79759 .{ }^{12}$ Therefore, understanding and addressing care provided is crucial when considering allocation of healthcare and social support funding and underscores the importance of promoting increased independence for those utilizing caregiving services.

The research evidence in this area to date has focused on those factors that precipitate a need for caregiving and the costs associated with care. This has predominantly been addressed in North American and European contexts; however, there has been no attempt to

${ }^{1}$ Faculty of Medicine, Graduate Program in Rehabilitation Sciences, University of British Columbia, Vancouver, British Columbia, Canada; ${ }^{2}$ Rehabilitation Research Program, Vancouver Coastal Health Research Institute, Vancouver, British Columbia, Canada; ${ }^{3}$ International Collaboration on Repair Discoveries, Vancouver, British Columbia, Canada; ${ }^{4}$ School of Social Work, Laval University, Quebec, Quebec, Canada and ${ }^{5}$ Department of Occupational Sciences and Occupational Therapy, Faculty of Medicine, University of British Columbia, Vancouver, British Columbia, Canada

Correspondence: Dr WC Miller, Department of Occupational Science and Occupational Therapy, Faculty of Medicine, University of British Columbia, T325-2211 Wesbrook Mall, Vancouver, V6T 2B5 British Columbia, Canada.

E-mail: bill.miller@ubc.ca

Received 14 July 2015; revised 14 December 2015; accepted 15 December 2015; published online 23 February 2016 
synthesize this information. In 2004, a review on the state of personal attendant services was published that focused on paid services to individuals with disabilities; however, it was not completed systematically and did not address those factors that are unique to individuals with SCI. ${ }^{13}$ To our knowledge, there has been no previous systematic review that has focused on the issues related to paid and unpaid caregiving specific to SCI, which therefore represents a gap in the research knowledge.

Pooling this knowledge in the form of a review can help us understand factors associated with successes and challenges in formal and informal caregiving, so they may be better addressed in clinical practice and offer insight into the gaps in the research to date. Such information can provide guidance for future research directions and lead to the development of interventions to improve the quality and consistency of caregiving services. This paper systematically reviews interventional and descriptive research to summarize the scientific literature related to the nature of caregiving services provided to individuals with SCI, identify gaps and limitations in the research knowledge and identify areas for future interventional research to address needs of care recipients.

\section{MATERIALS AND METHODS}

A multiple author review of literature was completed from January 1980 to December 2015. Keywords were generated from the literature and are displayed in Table 1. According to PRISMA guidelines, titles and abstracts generated through systematic search of CINAHL, Pubmed/Medline, EMBASE, PSYCINFO, Social Services Abstracts and Social Work Abstracts were reviewed for inclusion by a research assistant and one author (ES). Following abstract review, we completed a full-text review (by ES and NB) of all studies that met the inclusion criteria set $a$ priori. We included quantitative and qualitative peerreviewed studies written in English, which had a study population comprising at least $50 \%$ adults (over the age of 18 years), and described the nature of caregiving services in SCI, factors influencing the use of and access to caregiving services or described interventions to address caregiving needs of individuals with SCI. We included both qualitative and quantitative data to provide a richer investigation of the literature and to contribute to a broader understanding of the experiences of individuals with SCI receiving care. We excluded studies that specifically addressed the experiences of caregivers, and factors contributing to caregiver burden, as this is a distinct area of study that merits a separate review. Reference lists of included studies were reviewed by one author (ES) for any relevant articles not included in the database search, which were included if they met the criteria.

Data from included studies were extracted by a research assistant and one author (ES) according to a data-extraction matrix informed by the SCIRE research project. These individuals also rated the level of evidence (LOE) according to a simplified version of criteria by Sackett et al. ${ }^{14}$ these were verified by a second author (NB). The simplified criteria by Sackett et al. ${ }^{14}$ are described by the SCIRE project and represent five levels of evidence (reduced

\section{Table 1 Keyword searches}

Caregiving keywords

Attendant care

Personal care

Personal support

Home health aides

Community health nursing

Community health services

Health maintenance

Caregiv*

Sources searched: Pubmed/MEDLINE, CINAHL, Social Sciences Abstracts, Social Work Abstracts, EMBASE and PsycINFO. from ten) based on the study research design, from randomized controlled trials (Level 1) to observational data (Level 5). ${ }^{15}$ Analyses of extracted data were primarily descriptive and compared results between studies that were similar within this review.

\section{RESULTS}

A total of 2004 articles were identified following removal of duplicates. Of those, sixteen were selected for inclusion in this review, including five experimental studies and eleven descriptive (non-intervention) studies. See Figure 1 (PRISMA Diagram) for reasons for exclusion. The LOE for included studies ranged from 2 (highest) to 5 (lowest). Data were extracted according to SCIRE guidelines ${ }^{15}$ and are presented by the study with associated levels of evidence in Tables 2 and 3.

\section{Level of evidence}

The LOE for included studies ranged from 2 to 5, with 13 studies graded as level 5 studies, indicating a low-quality overall. The study with the highest LOE was a prospective (non-randomized) controlled trial.

\section{Results from descriptive studies}

Eleven studies described the nature of caregiving services, demographics of care recipients and caregivers and factors associated with requiring care. Table 2 lists descriptive studies that were included. Of these studies, one reported the results of research with caregivers themselves, ${ }^{9}$ nine reported research with individuals with $\mathrm{SCI}^{8,16-23}$ and one reported results of research with both caregivers and individuals with SCI. ${ }^{24}$ The study that reported research with caregivers only was specific to informal caregiving.

The majority of caregivers were noted to be informal care providers. $^{8,16}$ Of those studies including individuals with SCI who used both paid and unpaid caregiving, $37^{19}$ and $95 \%{ }^{20}$ of all caregivers were unpaid and/or informal. Veterans reported the lowest usage of informal caregivers (one-third). ${ }^{19}$ In those studies that provided information on the amount of care provided, mean care hours per day ranged from $2.3^{23}$ to $11.6,{ }^{19}$ with individual reports ranging from as low as $1 \mathrm{~h}$ per day to as high as $24 \mathrm{~h}$ per day. ${ }^{20}$ Informal caregivers included spouses, parents, siblings, children, friends and others. ${ }^{9,19,20,24}$ Across those studies that reported, caregivers were predominantly female. ${ }^{9,19,24,25}$

One study investigated factors that influence caregiver turnover and the impact of the turnover on people with SCI, noting that higher turnover was associated with fewer relatives or friends providing care. ${ }^{18}$ Overall quality of care did not appear to decline when working with informal caregivers. ${ }^{20}$ However, training for these individuals was limited to the time period following initial patient rehabilitation, during inpatient care or by the clients themselves. ${ }^{20} \mathrm{~A}$ separate study identified a need for education regarding secondary health conditions. $^{24}$ Three studies reported predictors of amount of care received. Higher number of caregiving hours were associated with higher self-reported disability status, ${ }^{21}$ level of neurological impairment, ${ }^{8}$ Functional independence measure (FIM) scores and lower capacity for IADL performance. ${ }^{8,23}$

\section{Results from experimental studies}

Five studies described interventions specific to caregiving (Table 3). All studies were conducted with people with SCI. One also included data collected from caregivers. Three studies investigated the impact of caregiver training on the provision of services, specifically the impact of training on knowledge of caregivers, and the relationship with their patients, ${ }^{25}$ training individuals with a variety of disabilities to work as 


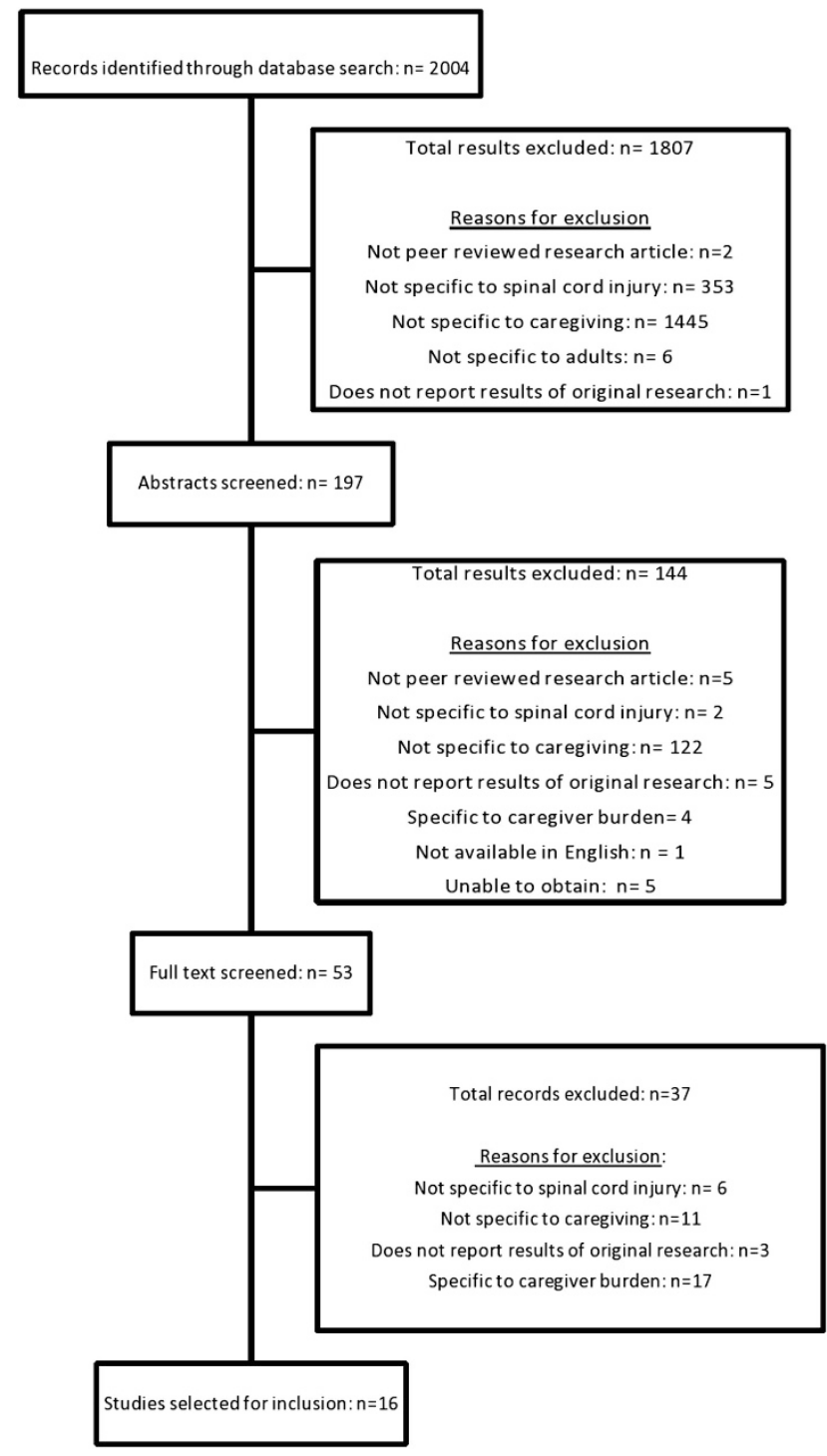

Figure 1 PRISMA flow diagram.

personal care attendants, ${ }^{26}$ and the impact of health maintenance education on the provision of care. ${ }^{27}$ Following training, caregivers had significantly greater knowledge about secondary health conditions, prevention of respiratory complications, spasticity, and autonomic dysreflexia, the effects of aging, and community services. ${ }^{25,27}$ Although a third study investigated a program training individuals with mental health issues, acquired brain injury, mental retardation, seizures and those going through drug and alcohol rehabilitation to work as personal care assistants, ${ }^{26}$ only one of eight study participants continued to receive care from his or her trained assistant at follow-up. ${ }^{26}$

One study reported the results of life care planning on the percentage of paid and unpaid care. ${ }^{28}$ Life Care Planning (LCP) is a process to create a document that establishes a plan for individuals with disabilities to meet their current and future needs and costs. ${ }^{29}$ This study found that planning increased hours of paid care and decreased percentage of unpaid hours. ${ }^{28}$ One additional study reported that individuals in self-managed care had significantly higher income, and employment, in addition to more hours of paid care, higher satisfaction with care and higher reported levels of health. ${ }^{30}$

\section{DISCUSSION}

The purpose of this review is to summarize and characterize the nature of caregiving services provided to individuals with SCI, to provide foundational knowledge of the factors associated with need for caregiving services and describe associated intervention programs.

\section{Description of caregivers}

Family and friends made up the majority of caregivers, ${ }^{8,16}$ which is consistent with previously published estimates that only $13.4 \%$ of adults receiving help with ADLs or IADLs in the United States were receiving care from paid caregivers. ${ }^{31}$ This differed for veterans, for whom only one-third reported care received primarily from informal carers ${ }^{19}$ which may be attributable to additional funding received through veterans pension programs.

A previous study found that sex may influence paid caregiving service use; males tend to rely on family members, whereas females are more likely to pay for services from an outside agency. ${ }^{32}$ This helps situate the data found in this review. As the primary caregivers are most often spouses, and the $80 \%$ of individuals with SCI are male, ${ }^{33}$ it is not surprising that the majority of informal carers reported in the

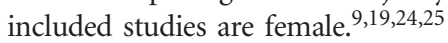

Estimates of the amount of informal care vary, with some reports ranging as low as $1 \mathrm{~h}$ per day and as high as $24 \mathrm{~h}$ of ongoing support. ${ }^{20}$ With the overwhelming reliance on family support, particularly spouses, it may be difficult to get a true understanding of the hours of care provided, given that care is likely provided on an ongoing basis. Caregivers also perform a range of duties and roles including support for ADLs, nursing care, prevention of secondary health conditions, housekeeping, emotional care and practical care (errands)., 16,17,22 The range of duties and roles identified in these studies may help explain the range in amount of informal care. Although some studies may have had clear operational definitions of what constituted care, these varied widely across studies. In this study, we defined caregiving services broadly as home-based supports (paid or unpaid) that assist individuals to perform basic and instrumental ADLs, which they would not otherwise be able to perform independently. ${ }^{4,5}$ However, this definition may not reflect the complexities of caregiving relationships. To develop a more complete analysis of the needs associated with caregiving in SCI, in addition to the costs and challenges associated, it would be helpful to have an established definition of the caregiving concept that could be used across contexts.

\section{Factors associated with caregiving need}

A number of studies specifically addressed factors associated with the need for caregiving, finding lower FIM and higher self-reported disability scores to be associated with higher number of hours of care provided. ${ }^{8,21,23}$ It is not surprising that individuals who have lower functional independence (FIM scores) are in need of more assistance for daily activities. Similarly, those who had more years post injury (that is, longer time since injury) also required less care, ${ }^{8}$ suggesting that those who are more experienced in managing their own conditions may have developed independence over time. None of the studies addressed the factors that influenced the decision to obtain or increase caregiving services, nor the impact of the place of residence on caregiving needs and decisions, representing gaps in the research literature. Investigation into these factors may provide more robust understanding of those factors that may be mitigated prior to the need for caregiving services. This additional knowledge could also contribute to higher quality interventional studies that could investigate the impact of addressing potentially modifiable factors such as functional independence, on the quantity of care provided. For 
Table 2 Descriptive studies

\begin{tabular}{lll}
\hline Author & Population (n) $\quad$ Purpose & Description of \\
Country & No. of female & \\
Study Design & $M A$ (years) & \\
LOE & $M Y P I$ & \\
& Subgroup information & \\
\hline
\end{tabular}

\begin{tabular}{|c|c|c|}
\hline $\begin{array}{l}\text { Guilcher et al. }{ }^{16} \\
\text { Canada }\end{array}$ & $\begin{array}{l}\text { Persons with } \mathrm{SCl} \\
(n=14)\end{array}$ & $\begin{array}{l}\text { Describe structure of informal networks, } \\
\text { understand influence on prevention and }\end{array}$ \\
\hline Cross-sectional/qualitative & 6 female & management of secondary health conditions \\
\hline LOE: 5 & $\begin{array}{l}M A=47.5 \\
M Y P I=18\end{array}$ & \\
\hline
\end{tabular}

Van Loo et al. ${ }^{17}$
The Netherlands
Cross-sectional
LOE: 5
Bushnik et al. ${ }^{18}$
USA
Observational
LOE: 5
Foster et al. ${ }^{9}$
Australia
Observational
LOE: 5

Robinson-Whelan and Rintala ${ }^{19}$

USA

Observational

LOE: 5

Weitzenkamp et al. ${ }^{8}$
USA
Observational
LOE: 5
Berry et al. ${ }^{20}$
USA
Observational
LOE: 5

\section{Samsa et al. ${ }^{21}$}

USA

Cross-sectional

LOE: 5

Manns and May²4

Canada $(n=453)$

158 female

$\mathrm{MA}=47.7$

$\mathrm{MYPI}=13.3$

Persons with $\mathrm{SCl}$

$(n=203)$

$\mathrm{MA}=47.0$

$\mathrm{MYPI}=19$

Persons with $\mathrm{SCl}$ and Examine family caregiving in $\mathrm{SCl}$ caregivers $(n=319)$

Family caregivers

( $n=179)$

Persons with $\mathrm{SCl}$

$(n=140)$

No females

Veterans with $\mathrm{SCl}$

$(n=384)$

$\mathrm{MA}=54.8$

Gain information on informal care received by veterans

Persons with SCI

( $n=2154)$

431 female

$\mathrm{MA}=36.9$ (11.4)

Persons with $\mathrm{SCl}$

$(n=22)$

5 female

Age range 20-36

years

with SCl living at home

Examine factors which influence

turnover

Gain information on attendant with $\mathrm{SCl}$
Persons with $\mathrm{SCl}$

Describe care needs for individuals

PCA turnover and impact of high PCA

$84.4 \%$ female

Assess predictors of PCA use in SCI

care arrangements for poor persons

Persons with $\mathrm{SCl}$

$(n=13542)$

$4 \%$ female

Persons with $\mathrm{SCl}$

$(n=35)$

12 female
Assess relationship between self-reported disability and caregiver hours received

Explore perceptions and needs for service delivery to improve long-term health
$62 \%$ spouses

$72.5 \%$ were $\geqslant 40$

years old

$87 \%$ living with indi-

viduals who have $\mathrm{SCl}$

$88 \%$ female

$59 \%$ spouse/partner

$17 \%$ parent

$9 \%$ siblings

$8 \%$ children

$2 \%$ friends

$3 \%$ others

10/14 identified as

Largest networks for social support, then physical assistance

Roles of caregivers:

(ii) Knowledge brokers

(iii) Advocacy

(iv) Preventing SHCs

(v) Assisting with finances

(vi) Managing SHCs

$72 \%$ require additional care

$19 \%$ need additional support for incidental ADLs $18.5 \%$ need additional support for housekeeping $8.6 \%$ have other additional needs

Higher turnover associated with fewer relatives or friends as PCAs

All individuals satisfied with skill level of PCAs High turnover associated with lower satisfaction with quality of care

$97.2 \%$ practical care (errands, groceries)

$87.6 \%$ emotional care

$67 \%$ physical care

$55.3 \%$ receive $\geqslant 3 \mathrm{~h}$ per day

$37 \%$ receive informal/unpaid care

Mean hours per day $=11.6$

$54 \%$ does not have anyone else willing and able

if caregiver is unable to care for them

58.2\% PCA unpaid

Increased neurological impairment and lower

FIM score associated with more care

Higher years post injury requires less care

5 spouses

2 cohabitators

All but 1 unpaid caregiver

12 other relatives

2 friends

15 trained in patient rehab

9 trained by patient

6 trained by nurses or

OT

8 trained by others

High correlation between self-reported disability (SRFM) and caregiver hours ( $r=-0.70$; for all) IADLs and SRFM items (total $r^{2}=0.102-0.273$ )

7 parents (4 female) 8 spouses ( 5 female) 2 siblings Strongest predictors of caregiver hours were Need for increased patient education and

1 caregiver

7 had 2 caregivers

2 had 4 caregivers

Hours per day range from 1 to 24

$15 / 22$ very satisfied with quantity, quality and dependability of care

information in the community, emphasis on 
Table 2 (Continued)

\begin{tabular}{|c|c|c|c|c|}
\hline $\begin{array}{l}\text { Author } \\
\text { Country } \\
\text { Study Design } \\
\text { LOE }\end{array}$ & $\begin{array}{l}\text { Population (n) } \\
\text { No. of female } \\
\text { MA (years) } \\
\text { MYPI } \\
\text { Subgroup information }\end{array}$ & Purpose & $\begin{array}{l}\text { Description of } \\
\text { caregivers }\end{array}$ & Results \\
\hline $\begin{array}{l}\text { Qualitative: focus Groups } \\
\text { LOE: } 5\end{array}$ & $\begin{array}{l}\mathrm{MA}=39 \\
\text { Caregivers }(n=23)\end{array}$ & & $\begin{array}{l}1 \text { child } \\
1 \text { aunt } \\
1 \text { grandparent }\end{array}$ & $\begin{array}{l}\text { continuity of care through primary care } \\
\text { prevention }\end{array}$ \\
\hline $\begin{array}{l}\text { Biering-Sorensen et al. }{ }^{22} \\
\text { Denmark } \\
\text { Cross-sectional } \\
\text { LOE: } 5\end{array}$ & $\begin{array}{l}\text { Persons with SCl } \\
(n=236) \\
43 \text { female } \\
\mathrm{MA}=50.5\end{array}$ & $\begin{array}{l}\text { To determine use of home aids, } \\
\text { adaptations or personal assistance } \\
\text { after traumatic } \mathrm{SCl}\end{array}$ & $\begin{array}{l}21 \% \text { unskilled care- } \\
\text { givers } \\
33 \% \text { paid domestic } \\
\text { help } \\
8 \% \text { home nurses } \\
18 \text { spouses } \\
5 \text { cohabitators } \\
1 \text { parent } \\
1 \text { child }\end{array}$ & $\begin{array}{l}98.7 \% \text { sample living in own home } \\
21 \% \text { receive personal help; mean } 77.6 \mathrm{~h} \text { per } \\
\text { week, mostly unskilled, most common in } \\
\text { tetraplegic and youngest participants } \\
33 \% \text { receive domestic help, used by municipal- } \\
\text { ity, median } 2.5 \mathrm{~h} \text { per week } \\
\text { Most common for oldest and women } \\
8 \% \text { receive home nurse, median } 1 \mathrm{~h} \text { per week, } \\
\text { most common for tetraplegic women } \\
\text { Mean minutes assistance per day }=136.07 \\
\text { (range } 1-503 \text { ) } \\
\text { Mean hours of paid help per day }=9.63 \text { (range } \\
0.04-30 \text { ) } \\
\text { Strong correlation ( } r=-0.92 \text { ) between root of } \\
\text { minutes of assistance and FIM18/FIM Motor } \\
\text { scores } \\
85 \% \text { variance explained by FIM scores } \\
\text { Correlation between root of hours paid help } \\
\text { per day and FIM18/FIM Motor scores ( } r=-0.76 \text { ) } \\
58 \% \text { variability explained by FIM18/FIM Motor } \\
\text { model demonstrates that FIM18 score of } \geqslant 121 \\
\text { requires no assistance. }\end{array}$ \\
\hline
\end{tabular}

Abbreviations: ADL, activities of daily living; FIM, functional independence measure score; IADL, instrumental ADL; LOE, level of evidence; MA, mean age; MYPI, mean years post-injury; PCA, personal care attendants; SCI, spinal cord injury; SHC, secondary health condition; SRFM, self-reported functional measure.

example, a randomized controlled trial could compare those who receive tailored rehabilitation services in the community designed to improve functional independence with those who do not, to determine whether care needs could be reduced through direct service provision.

\section{Challenges associated with informal care}

According to Berry et al., ${ }^{20}$ the quality of care received from informal caregivers appears to match or exceed that received from more formalized carers, when considering quantity, quality and dependability of care received. In a study comparing satisfaction with care to high or low carer turnover rates, groups were equally satisfied with the skill level of their caregivers, but the high turnover group (involving more formal care providers) was less satisfied with the quality of care. ${ }^{18}$ This suggests that the quality of care provided by informal caregivers, who made up the majority of the low turnover group, is perceived as equal to or better than that received by formal caregivers. ${ }^{18}$ Despite this finding, there are no studies that compare the care received between formal and informal care directly, according to established metrics for quality, caregiver skill and related health outcomes. Additional research could investigate those variables and interventions that could enhance the care provided, by both formal and informal caregivers.

Individuals also reported that the high turnover of formal caregivers restricted daily life more than low turnover ${ }^{18}$ and also reported a higher quality of life with family and friends as caregivers. ${ }^{18}$ These differences may be a reflection on the amount of time provided by informal caregivers or the intimate knowledge of the individuals' needs due to family or friend relationships. There may be factors that impact both turnover and perceived quality of care. For example, informal caregivers may be unable to make choices regarding working conditions, due to the nature of their relationship with the care recipient. Formal caregivers are less likely to provide care 'above and beyond' what is contracted, which may influence the perception of the care received and may also have a role in high turnover rates. There is an opportunity for research that investigates both the impact of high turnover and also the factors contributing to this phenomenon, which could address any potential consequences.

Despite a relatively high level of perceived quality of care, Manns and $\mathrm{May}^{24}$ identified a number of associated concerns including the need for increased education, particularly regarding secondary health conditions. Schopp et al. ${ }^{25}$ (discussed below) report on a personal assistant service training program that targets this concern specifically. ${ }^{25}$ This is an area where further research and clinical work would be warranted.

The longevity of caregiving relationships in informal care arrangements was evident as $25 \%$ of veterans felt that their caregiver would continue to provide the same amount of care in 5 years $;^{19}$ however, $54 \%$ did not have anyone other than their primary caregiver who would be willing or able to provide care if the primary caregiver became unable to provide the service. ${ }^{19}$ This is likely true for the majority of individuals receiving care from informal networks 
Table 3 Experimental studies

\begin{tabular}{|c|c|c|c|}
\hline Author & Population (n) & Intervention & Results \\
\hline Country & No. of female & Outcome measure & \\
\hline Design & MA (years) & & \\
\hline \multirow[t]{2}{*}{$L O E$} & MYPI & & \\
\hline & Subgroup infor & & \\
\hline
\end{tabular}

\begin{tabular}{|c|c|c|}
\hline Owen and Marini28 & People with SCI $(n=55)$ & Life care planning \\
\hline USA & 22 female & Life care survey (hours and nature of care \\
\hline \multicolumn{3}{|l|}{$\begin{array}{l}\text { Cross-sectional/ } \\
\text { qualitative }\end{array}$} \\
\hline LOE: 5 & & \\
\hline
\end{tabular}

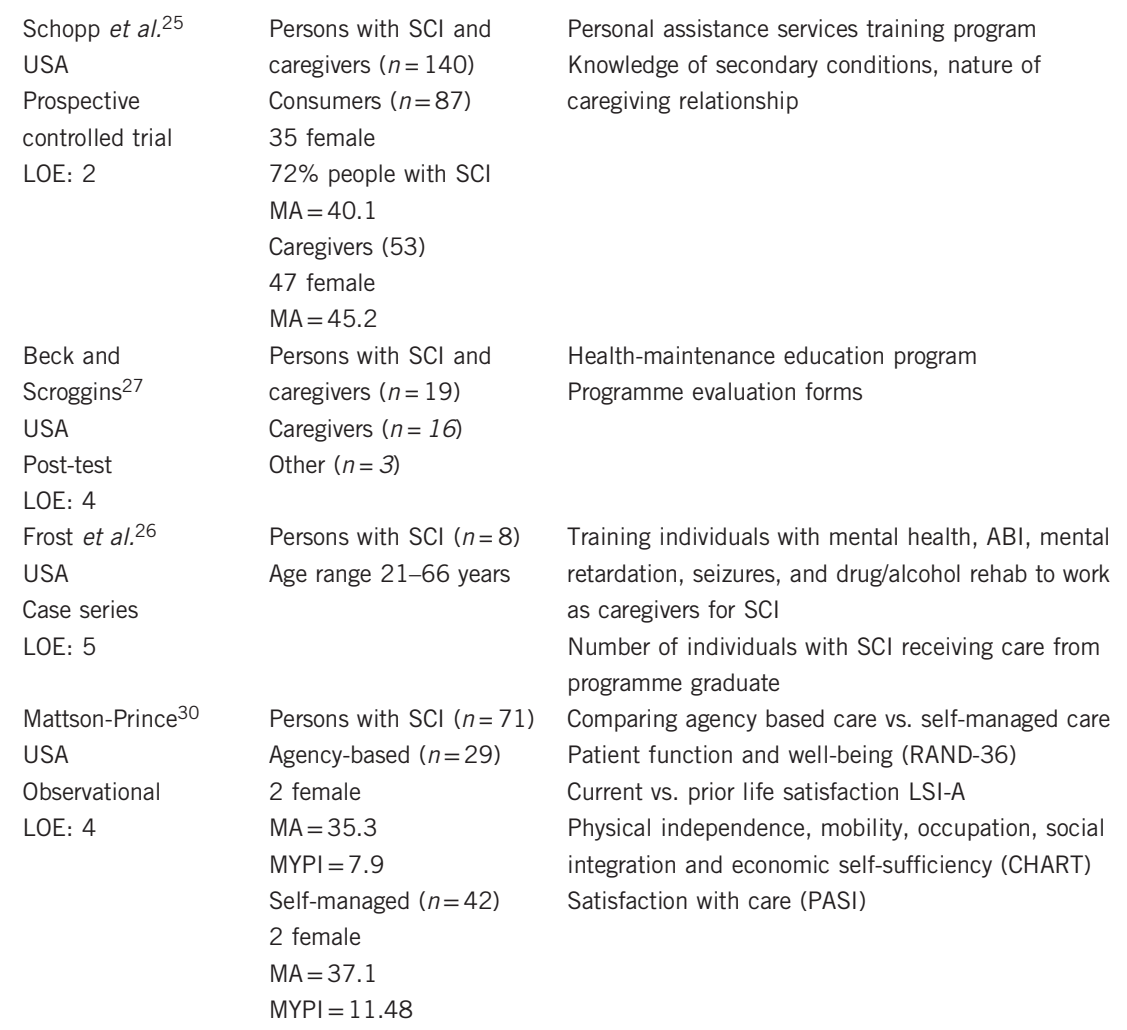

\author{
Pre life care plan: \\ 67.65 unpaid \\ $17.65 \%$ paid (agency), $14.71 \%$ paid (private) \\ Unpaid daily hours $=12.92$ \\ Paid daily hours $=5.81$ \\ Post life care plan: \\ $33.38 \%$ unpaid, \\ $46.88 \%$ paid (private), $18.75 \%$ paid (agency) \\ Unpaid daily hours 10.88 \\ Paid daily hours $=7.89$ \\ Consumers and caregivers had significantly higher knowledge \\ about SHCs 3 and 6 months post intervention than those in \\ control \\ No differences between groups in working relationship
}

Statistically significant increase in knowledge of prevention of respiratory complications, spasticity and autonomic dysreflexia, reported symptoms, effects of aging, community resources

\section{$1 / 8$ receiving care from project graduate on follow-up}

Individuals in self-managed care had significantly higher income and employment

Agency-based care had lower spinal cord lesions

Self-managed care had significantly more hours of paid care, higher satisfaction with care, higher reported level of health No difference between groups in current vs. pre-injury life satisfaction

Abbreviations: LOE, level of evidence; MA, mean age; MYPI, mean years post-injury; SCI, spinal cord injury; SHC, secondary health condition.

and represents a substantial social liability, particularly when one considers the potential impact of caregiver burden and burnout. This phenomenon has been described in a number of studies in the SCI literature; ${ }^{34-36}$ however, has not been synthesized, and is an area that would benefit from future attention.

\section{Interventions on caregiving}

The quality of the intervention studies was generally low, with no randomized controlled trials comparing interventions to one another. Given the high costs and potential burden associated with caregiving services, this represents a gap in the literature that should be addressed. The development of high-quality interventional studies that aim to improve the quality of care received, the health outcomes of individuals with spinal cord injuries and the costs associated with care provision would provide substantial benefit to the field of SCI rehabilitation.

Berry et $a .^{20}$ reported on the training received by informal caregivers; the majority were trained while the family member or friend was undergoing initial inpatient rehabilitation, with training by the client themselves, nurses or Occupational Therapists or others involved in their inpatient care. Such training is by nature limited in scope and does not reflect the changing needs of clients over time. A study on the effects of aging in SCI suggests that increases in fatigue and decreased activity are significantly associated with age-those who live longer with SCI experience increases in symptoms and illness and greater threats to health. ${ }^{37}$ This contrasts with the study discussed above, which indicated that individuals who were further post injury required fewer hours of care. ${ }^{8}$ However, it is important to note the 
mean age in this study was 36.7 years; hence, this may not reflect the realities of aging into the senior years with an SCI. To date there has not been substantial attention paid to the issues inherent in aging with SCI, and a further exploration of this issue may provide additional context, which informs caregiving needs in the future. It is likely that we may expect an increase in care demands over time, necessitating more advanced care, for which informal caregivers are not prepared and would contribute to increased caregiver burden. In the literature pertaining to caregiving following stroke, caregiver training was found to lessen the impact of age and severity of illness on caregiver burden and quality of life, underscoring the importance of these programs for informal caregivers. ${ }^{38}$ Future work may focus on the experience of caregiver burden and interventions that alleviate the impact of caring on caregivers of individuals with SCI.

An intervention specifically investigating life care planning may be one avenue through which individuals can exert more control over their care arrangements. Following completion of LCP, the number of unpaid caregiving hours decreased and paid hours increased. ${ }^{28}$ The increase in hours of paid care was seen most markedly in the amount of private hire paid care (from $14.71 \%$ before LCP to $46.88 \%$ after), whereas there was virtually no difference in paid agency care. All gains in private care were taken directly from unpaid, informal care. ${ }^{28}$ On the basis of this study, LCP could be an effective intervention to reduce reliance on informal caregivers. However, it is important to consider the impact this might have on quality of care. As identified above, reducing the number of unpaid hours in favor of paid care may influence the quality of care received.

Two interventional studies did address issues of training for formal caregivers. Both personal assistant services training ${ }^{25}$ and a health maintenance education program ${ }^{27}$ offered benefits in terms of knowledge of, prevention, and treatment of secondary health conditions, and access to resources. A large randomized controlled trial on caregiver training demonstrated the ability to reduce costs associated with caring, reduce caregiver burden, anxiety and depression, and improve patients' quality of life. ${ }^{39,40}$ Although it is possible that additional caregiver training for clients with SCI may improve client outcomes and reduce caregiver burden, these ideas are not yet supported in the literature. The relative lack of research in this area in SCI highlights a gap in our knowledge, which should be addressed.

\section{LIMITATIONS}

This review was limited by the relative lack of high-quality interventional data available specific to caregiving services in SCI. Levels of evidence varied widely; all descriptive studies were classified as Level 5 evidence, four interventional studies met the criteria for level 4 evidence, and one met the criteria for level 2 evidence. Of the sixteen included studies, only five reported results of intervention, whereas the rest were descriptive (including both qualitative and quantitative methodologies). Studies included for review represent a time span of 20 years (1995-2015). Therefore, all studies may not be representative of the current landscape of caregiving in SCI. In addition, there was substantial heterogeneity in the published literature. As a result, this is a review of caregiving in SCI as it has been studied to date and provides direction for future research, rather than providing specific conclusions on which clinical recommendations may be made. In addition, only English language studies were included, which may introduce bias by not identifying the results of studies conducted or published in other languages.

\section{Future directions}

We have identified a number of areas for future research in the discussion; however, there are two that we found repeated often and bear additional attention. As the majority of caregivers are informal in nature, interventions including education may improve the skills and capacities of informal carers. These interventions may be well placed in the inpatient care setting or at home upon discharge from inpatient rehabilitation. Given the longevity of informal caregiving relationships, interventions investigating the role of ongoing training for informal caregivers may also help reduce cost, improve day-to-day function and quality of life of clients and reduce overall caregiver burden as needs change over the life span.

There is a substantial body of literature on the impact of caregiving on the caregiver, which we did not include in this study. This is an area that would warrant future research, particularly given the findings that the majority of caregivers are informal in nature. Many individuals may not have alternate means of care available to them should they no longer be able to provide care. We have also identified a gap in the research understanding specific to the impact of aging in SCI. This could have an additional impact on caregiving needs and the nature of caregiving services, as family caregivers will experience additional burden as both they and their care recipients age.

\section{CONCLUSION}

Caregiving services for individuals with SCI are predominantly provided by informal caregivers, of whom the majority are female. Total hours of care are dependent on the injury level and severity, and the care needs of the individual. Although intervention-based research is currently limited, and the LOE that does exist is generally quite low, training for caregivers is an important theme and has positive preliminary results on the quality of care provided. Cross-sectional research suggests that higher individual function contributes to increased independence and decreased need for care; however, a research gap remains regarding additional factors that may contribute to care needs. This supports further research investigating ongoing training for caregivers and interventions that may reduce the need for additional care for individuals with SCI. Evidence-based interventions that reduce reliance on caregivers through increased independence, or those that improve or sustain quality of care provided, could enhance the experience of care recipients, address issues of caregiver burden, reduce overall costs associated with SCI and ultimately improve social participation of persons with SCI.

\section{CONFLICT OF INTEREST}

The authors declare no conflict of interest.

\section{ACKNOWLEDGEMENTS}

We acknowledge the support of the SCIRE Research Team for their assistance with the preparation of this manuscript and the support of the GF Strong Rehabilitation Research Program, Vancouver Coastal Health Research Institute. Emma Smith is supported by a doctoral scholarship from the Alzheimer Society of Canada.

1 Strauss DJ, DeVivo MJ, Paculdo DR, Shavelle RM. Trends in life expectancy after spinal cord injury. Arch Phys Med Rehabil 2006; 87: 1079-1085.

2 Adams M, Beatty P. Consumer-directed personal assistance services: Independent living, community integration and the vocational rehabilitation process. J Vocat Rehabil 1998; 10: 93-101.

3 Noreau L, Fougeyrollas P. Long-term consequences of spinal cord injury on social participation: the occurrence of handicap situations. Disabil Rehabil 2000; 22: 170-180. 
4 Cockerill R, Durham N. Attendant care and its role in independent living as developed in transitional living centres. N Engl J Hum Serv 1992; 11: 17-22.

5 Pomeranz J, Shaw L, Sawyer H, Velozo C. Consensus among life care planners regarding activities to consider when recommending personal attendant care services for individuals with spinal cord injury: a Delphi study. J Life Case Plan 2006; 5: 7-22.

6 Andersson A, Levin L-A, Emtinger BG. The economic burden of informal care. Int J Technol Assess Health Care 2002; 18: 46-54.

7 Krueger H, Noonan VK, Trenaman LM, Joshi P, Rivers CS. The economic burden of traumatic spinal cord injury in Canada. Chronic Dis Inj Can 2013; 33: 113-122.

8 Weitzenkamp DA, Whiteneck GG, Lammertse DP. Predictors of personal care assistance for people with spinal cord injury. Arch Phys Med Rehabil 2002; 83: 1399-1405.

9 Foster M, Amsters D, Carlson G. Spinal cord injury and family caregivers: a description of care and perception of service need. Aust J Prim Health 2005; 11: 91.

10 Boschen K, Gargaro J, Tonack M. Community integration and quality of life comparisons among spinal cord injured, support provider, and comparative samples. Top Spinal Cord Inj Rehabil 2005; 10: 116-134.

11 Boschen K, Tonack M, Gargaro J. The impact of being a support provider to a person living in the community with a spinal cord injury. Rehabil Psychol 2005; 50: 397-407.

12 DeVivo M, Chen Y, Mennemeyer S, Deutsch A. Costs of care following spinal cord injury. Top Spinal Cord Inj Rehabil 2011; 16: 1-9.

13 Hagglund KJ, Clark MJ, Mokelke EK, Stout BJ. The current state of personal assistance services: implications for policy and future research. NeuroRehabilitation 2004; 19: $115-120$.

14 Sackett DL, Straus SE, Richardson W, Rosenberg W, Haynes R. Evidence Based Medicine: How to Practice and Teach EBM. Churchill Livingstone: Toronto, Ontario, Canada, 2000

15 Eng JJ, Teasell R, Miller WC, Wolfe DL, Townson AF, Aubut JA et al. Spinal cord injury rehabilitation evidence: methods of the SCIRE Systematic Review. Top Spinal Cord Inj Rehabil 2007; 13: 1-10.

16 Guilcher SJT, Casciaro T, Lemieux-Charles L, Craven C, McColl MA, Jaglal SB. Social networks and secondary health conditions: the critical secondary team for individuals with spinal cord injury. J Spinal Cord Med 2012; 35: 330-342.

17 Van Loo M, Post MWM, Bloemen J, van Asbeck FW. Care needs of persons with longterm spinal cord injury living at home in the Netherlands. Spinal Cord 2010; 48 423-428.

18 Bushnik T, Wright J, Burdsall D. Personal attendant turnover: association with level of injury, burden of care, and psychosocial outcome. Top Spinal Cord Inj Rehabil 2002; 81: 798-800.

19 Robinson-Whelan S, Rintala D. Informal care providers for veterans with SCl: who are they and how are they doing. J Rehabil Res Dev 2003; 40: 511-516.

20 Berry J, Hitzman S, Stewart G, Darwin P. A survey of attendant care arrangements in indigent persons with spinal cord injury. SCI Psychosoc Process 1995; 8: 112-117.

21 Samsa GP, Hoenig H, Branch LG. Relationship between self-reported disability and caregiver hours. Am J Phys Med Rehabil 2001; 80: 674-684.

22 Biering-Sørensen T, Hansen RB, Biering-Sørensen F. Home aids and personal assistance 10-45 years after spinal cord injury. Spinal Cord 2009; 47: 405-412.
23 Hamilton BB, Ms AD, Russell C, Fiedler RC, Granger CV. Relation of disability costs to function: spinal cord injury. Arch Phys Med Rehabil 1999; 80: 385-391.

24 Manns PJ, May La. Perceptions of issues associated with the maintenance and improvement of long-term health in people with SCI. Spinal Cord 2007; 45: 411-419.

25 Schopp LH, Clark MJ, Hagglund KJ, Mokelke EK, Stout BJ, Mazurek MO. Evaluation of a consumer-personal assistant training project. Disabil Rehabil 2007; 29 403-410.

26 Frost F, Brennan D, Roach M. Opportunities in community placement: an innovative personal care assistant training program in the inner city. Top Spinal Cord Inj Rehabil 1999; 4: 94-102.

27 Beck LA, Scroggins LM. Optimizing health of individuals with tetraplegia. SCI Nurs 2001; 18: 181-186.

28 Owen T, Marini I. Attendant care and spinal cord injury: usage patterns and perspectives for those with life care plans. J Life Care Plan 2012; 10: 33-44.

29 Johnson CB, Weed RO. The life care planning process. Phys Med Rehabil Clin N Am 2013; 24: 403-417.

30 Mattson-prince J. A rational approach to long term care : comparing the independent living model with agency-based care for persons with high spinal cord injuries. Spinal Cord 1997; 35: 326-331.

31 LaPlante M, Kennedy J, Kaye S, Wenger B. Disability statistics. US Dep Educ NatI Inst Disabil Rehabil Res 2002; 23: 1-4. abstract: No 23.

32 Shackleford M, Farley T, Vines C. A comparison of women and men with spinal cord injury. Spinal Cord 1998; 36: 337-339.

33 Spinal Cord Injury Model Systems Spinal Cord Injury Facts and Figures at a Glance. 2014. Available at: https://www.nscisc.uab.edu/PublicDocuments/fact_figures_docs/ Facts\%202014.pdf (accessed 10 December 2015).

34 Unalan H, Gençosmanoğlu B, Akgün K, Karamehmetoğlu S, Tuna H, Ones K et al. Quality of life of primary caregivers of spinal cord injury survivors living in the community: controlled study with short form-36 questionnaire. Spinal Cord 2001; 39: 318-322.

35 Schulz R, Czaja SJ, Lustig A, Zdaniuk B, Martire LM, Perdomo D. Improving the quality of life of caregivers of persons with spinal cord injury: a randomized controlled trial. Rehabil Psychol 2009; 54: 1-15.

36 Rodakowski J, Skidmore ER, Rogers JC, Schulz R. Role of social support in predicting caregiver burden. Arch Phys Med Rehabil 2012; 93: 2229-2236.

37 Pentland W, McColl MA, Rosenthal C. The effect of aging and duration of disability on long term health outcomes following spinal cord injury. Paraplegia 1995; 33 367-373.

38 McCullagh E, Brigstocke G, Donaldson N, Kalra L. Determinants of caregiving burden and quality of life in caregivers of stroke patients. Stroke 2005; 36 2181-2186.

39 Patel A, Knapp M, Evans A, Perez I, Kalra L. Training care givers of stroke patients: economic evaluation. BMJ 2004; 328: 1102

40 Kalra L, Evans A, Perez I, Melbourn A, Patel A, Knapp M et al. Training carers of stroke patients: randomised controlled trial. BMJ 2004; 328: 1099 